\title{
Effect of daily versus weekly home fortification with multiple micronutrient powder on haemoglobin concentration of young children in a rural area, Lao People's Democratic Republic: a randomised trial
}

Sengchanh Kounnavong ${ }^{1,2^{*}}$, Toshihiko Sunahara², C G Nicholas Mascie-Taylor ${ }^{3}$, Masahiro Hashizume², Junko Okumura², Kazuhiko Moji ${ }^{4}$, Boungnong Boupha ${ }^{1}$ and Taro Yamamoto ${ }^{2}$

\begin{abstract}
Background: Multiple micronutrient deficiencies, in particular iron deficiency anaemia (IDA) is a severe public health problem in Lao People's Democratic Republic (Lao PDR). Because of the practical difficulties encountered in improving the nutritional adequacy of traditional complementary foods and the limitations associated with the use of liquid iron supplementation for the treatment and prevention of IDA in infants and young children, recently, home-fortification with multivitamins and minerals sprinkles was recommended. This study aims to compare the effect of twice weekly versus daily supplementation with multivitamins and minerals powder (MMP) on anaemia prevalence, haemoglobin concentration, and growth in infants and young children in a rural community in Lao PDR.

Methods: A randomized trial was conducted in six rural communities. Children aged 6 to 52 months $(n=336)$ were randomly assigned to a control group $(n=110)$ or to one of two intervention groups receiving either two sachets per week $(n=115)$ or a daily sachet $(n=111)$ of MMP for 24 weeks; 331 children completed the study. A finger prick of blood was taken at baseline, at week 12, and again at week 24 to determine haemoglobin concentration. Anthropometric measurements were taken every 4 weeks. The McNemar test was used to assess within group differences at three time points in the study subjects with anaemia and one-way ANOVA was used to assess changes in mean haemoglobin concentration in the treatment groups.

Results: MMP supplementation resulted in significant improvements in haemoglobin concentration and in the reduction of anaemia prevalence in the two treatment groups compared with the control group $(p<0.001)$. The severely to moderately anaemic children $(\mathrm{Hb}<100 \mathrm{~g} / \mathrm{L})$ on daily supplementation recovered faster than those on twice weekly supplementation. MMP was well accepted and compliance was high in both treatment groups. Overall, the improvement in the weight for age Z-score was very small and not statistically significant across the three study groups.

Conclusions: MMP supplementation had positive effects in reduction of anaemia prevalence and in improving haemoglobin concentration. For severely to moderately anaemic children, daily MMP supplementation was more effective in improving haemoglobin concentration and reducing anaemia prevalence. A longer intervention period is probably needed to have a positive effect on growth.
\end{abstract}

Keywords: Anaemia, multiple micronutrient powder, supplementation, home fortified food, Lao PDR

\footnotetext{
* Correspondence: sengchanhkounnavong@hotmail.com

'National Institute of Public Health, Ministry of Health, Vientiane, Lao

People's Democratic Republic

Full list of author information is available at the end of the article
} 


\section{Background}

According to UNICEF/WHO/WFP, micronutrient or vitamin and mineral deficiencies affect approximately 2 billion people worldwide [1]. The adverse effects of micronutrient deficiencies during childhood are substantial. Micronutrient deficiencies have negative effects on growth and development, and cause reduced psychomotor performance, and increased morbidity and mortality [2-8].

The main cause of the multiple deficiencies is a poor quality diet, often as the result of an inadequate intake of animal sources of foods. Additionally, non-nutritional factors such as parasitic infections, genetic haemoglobinopathies, malaria, and infectious diseases impair nutritional status and health and alter the metabolism of multiple micronutrients [9]. Infants and young children are particularly at risk of micronutrient deficiencies. From the age of 6 months, the nutrient requirements of infants need to be met by breast milk and complementary foods. Although possible modifications to the traditional recipes, such as adding extra animal source foods and reducing absorption-inhibiting components such as phytate, were considered, the diet would still be unlikely to meet the requirements for micronutrients such as iron, calcium, and zinc. Additionally animal source foods alone may not provide enough vitamins and minerals for young children [10,11]. Therefore, in developing countries, micronutrients are very likely to continue to be limited in the diets of young children between the ages of 6 and 23 months. This problem also applies in Lao People's Democratic Republic (Lao PDR) where the quality of complementary food, that is predominantly cereal-based, is very poor[12]. Thus, for children aged 6-23 months, vitamins and minerals need to be added to their diets to improve development and growth and reduce morbidity and mortality[9].

Anaemia, which is mainly due to iron deficiency, is one of the major micronutrient deficiencies in developing countries. In the Lao PDR Multiple Indicator Cluster Survey 2006 and the Lao PDR National Nutrition Survey 2006, the prevalence of anaemia in children 6-59 months of age was reported to be $41 \%$. The prevalence was much higher (63.5\%) in children aged 6-23 months [13]. According to the World Health Organization (WHO), over $40 \%$ prevalence of anaemia indicates a very severe public health problem [14].

Because of the practical difficulties encountered in attempts to improve the nutritional adequacy of traditional complementary foods [15] and the limitations associated with the use of liquid iron supplementations for the treatment and prevention of iron deficiency anaemia (IDA) in infants and young children[16] and because multiple deficiencies coexist with IDA, home fortification with multivitamins and minerals in a powdered form, known as sprinkles, has been widely promoted as a way to address IDA and micronutrient deficiencies [17-25]. One of the main benefits of sprinkles is that they can be easily incorporated into the currently recommended complementary feeding practices for infants after 6 months of age and can therefore contribute to healthy infant weaning practices [26].

However, the effect of adding sprinkles to home-prepared foods may depend on the local food culture and acceptance by local people. Therefore, the multivitamins and minerals powder needs to be tested locally to clarify the optimal starting point, the duration of use, and its acceptability [27]. A previous study in young Vietnamese children found that weekly supplementation with multiple micronutrients was as effective as daily supplementation in improving haemoglobin concentration and proposed that weekly instead of daily supplementation was cheaper and program compliance may be better [28].

The primary aim of the present study was to compare the effects of multivitamins and minerals powder (MMP) given as two sachets on 2 separate days during the week with one sachet given daily on haemoglobin concentration, the prevalence of anaemia, and growth in infants and young children. We also aimed to assess MMP compliance for the two regimens and the acceptability of the product among the mothers or caretakers of the study subjects.

\section{Methods}

\section{Study area}

This study was conducted in six communities in the Lahanam zone, Songkhone District, Savannakheth Province, $600 \mathrm{~km}$ south of the capital city, Vientiane, Lao PDR. The Health and Demographic Surveillance System (HDSS) was established in this area in 2004 and all the population is registered.

The Lahanam area has a relatively high production of rice, cotton and watermelon, and most villagers have access to adequate amounts of rice. Other foodstuffs are seasonally available from nearby small patchy forests and from the market town (within $10 \mathrm{~km}$ of the Lahanam area). Intake levels of fat, calcium, iron, and retinal in the area were found to be very low compared with the recommended dietary allowance of Thailand and the WHO/FAO [29].

The first complementary food that is used in the area is principally glutinous rice, which is given pre-chewed by mothers to nearly all infants in the first week of their life. This traditional early use of complementary food may decrease or stop the infant's intake of breast milk [30]. 
There is only one health centre in the area providing primary health care. This centre serves a population of 7,000 through six auxiliary nurses and an average of two village health volunteers (VHVs) in each village. A malaria control program was successfully executed in all the villages 10 years ago. Each household was categorized into one of two socioeconomic status groups: high (with electricity, improved water source and latrine) and low (lacking one or all of these).

\section{Study design and randomization}

The study was a randomized trial. A statistical power analysis $(80 \%$ power and significance of $p=0.05)$ showed that to reduce anaemia by $20 \%$ (from $41 \%$ to $21 \%$ ) and to improve haemoglobin concentration by $0.56 \mathrm{~g} / \mathrm{L}$, and to compensate for $10 \%$ loss to follow-up, a sample size of 110 children would be needed in each group.

In an effort to promote community participation, a series of meetings with local authorities (heads of the villages), parents, VHVs, and health centre staff were held before commencement of the study to explain the study objectives. Individual written informed consent was obtained at the time of enrolment from the mothers or legal guardians of all the children involved in the study. The study was approved by the Nagasaki University Ethical Review Board (Japan) and the National Ethic Committee for Health Research of the Ministry of Health in Lao PDR.

From the HDSS database of the National Institute of Public Health (NIOPH), 367 eligible pre-school age children were identified. Inclusion criteria were: (i) age 6 to 53 months at the time of recruitment; (ii) willingness to participate; (iii) receiving complementary food in addition to breast milk; and (iv) apparently healthy. Exclusion criteria were: (i) having fever or any illnesses on the day of enrolment; (ii) baseline level of haemoglobin less than $70 \mathrm{~g} / \mathrm{L}$; and (iii) currently receiving iron supplementation. Of the original 367 children who met the criteria, 17 were absent at the time of enrolment, and 14 were excluded because they had infections with fever on the day of enrolment. Therefore, a total of 336 children were enrolled in the study.

Before recruitment began, we used a simple computer program (a random number generator) for the randomization process, which was done by household. We then enrolled the 336 eligible children and randomly allocated them to three groups: a control group $(\mathrm{n}=111)$, a group given twice weekly multiple micronutrients supplementation $(\mathrm{n}=115)$, and a group given daily multiple micronutrients supplementation $(\mathrm{n}=111)$. Children in families with two or more children who fulfilled the requirements to participate in the study were all included and treated as separate cases; however, all the children in one family were allocated to the same group. There were 215 onechild families, 49 families with two children, and three families with four children in the study.

As part of the routine government health services, all children below the age of five years received a single high dose of vitamin A every 6 months, and those aged 24 months or older received a single dose of mebendazole for deworming in the 2 months prior the study. Children who had not received mebendazole were given it during the baseline survey.

Over 24 weeks, the daily group was given MMP supplementation from Monday to Sunday (7 d/wk), and the twice weekly group was given MMP supplementation on Monday and again on Friday. Because of technical and financial constraints, placebo could not be produced locally, so following the normal standard of care in Lao PDR at the time of the study; the control group received the 6-monthly high-dose vitamin A supplementation instead of a placebo. After completing this study, all subjects in the control group received 60 sachets of MMP.

\section{Micronutrient supplements}

The MMP supplement used in this study was MixMe ${ }^{\mathrm{TM}}$ manufactured by DSM Nutritional Products Europe, Ltd., CH 4002 Basel. The nutrients and amounts used in the multi-micronutrient formula are based on the recommendations by UNICEF/WHO/WFP for one recommended dietary allowance of 15 vitamins and minerals. The nutrient content of $1 \mathrm{~g}$ of MMP was vitamin A (RE $400 \mu \mathrm{g})$, vitamin D3 $(5 \mu \mathrm{g})$, vitamin E (TE 5 $\mathrm{mg})$, vitamin B1, B2, B6 each (0.5 mg), folic acid (150 $\mu \mathrm{g})$, niacin $(6 \mathrm{mg})$, vitamin B12 $(0.9 \mu \mathrm{g})$, vitamin C (30 $\mathrm{mg})$, iron $(10 \mathrm{mg})$, zinc $(4.1 \mathrm{mg})$, selenium $(17 \mu \mathrm{g})$, copper $(0.56 \mathrm{mg})$, and iodine $(90 \mu \mathrm{g})$. The MMP was supplied in a single-dose sachet ( 1 dose $=1$ sachet) and one pack contained $30 \times 1 \mathrm{~g}$ sachets.

The doses of micronutrients used in this study were calculated based on the WHO recommendation on the dosage schedules for iron supplementation to prevent IDA [14]. Indications for supplementation are when the diet does not include foods fortified with iron or when anaemia prevalence is above $40 \%$. It is recommended that children from 6 to 23 months of age should receive $2 \mathrm{mg}$ of iron per $\mathrm{kg}$ body weight per day and children from 24 to 59 months of age should receive the same dose, up to a maximum of $30 \mathrm{mg}$ per day, for 3 months.

The dose of iron in the MMP used in this study was $10 \mathrm{mg}$, which is within the range of daily recommended dosage of iron for young children according to the American Food and Drug Administration. A total of 168 sachets were provided to the daily supplementation group and 48 sachets were given to the twice weekly supplementation group. 


\section{Data collection}

The study commenced in February 2009 with focus group discussions and in-depth interviews with mothers and field promoters (VHVs and members of the Lao Women's Union) to gather information on current child feeding practices and on how to introduce and promote MMP supplementation for children. This phase was completed in March 2009 with a baseline survey in all six communities. Mothers or legal guardians were invited to a central setting such as a health centre or temple in each of the villages, and interviews were conducted by the medical staff from the NIOPH. Information was gathered on; (i) family characteristics including mother's education level, working status (working outside or at home), ownership of latrine, and access to improved water sources; (ii) feeding practices, noting the age of starting complementary foods, the type of complementary foods, and number of meals consumed per day; (iii) knowledge of anaemia; and (iv) medical history (occurrence of diarrhoea or cough in the previous 2 weeks and receipt of routine deworming treatment). After this, the MMP supplementation intervention began, lasted for 24 weeks, and ended in October 2009.

\section{Assessment of haemoglobin concentration}

At weeks 0, 12 and 24 of the study, capillary blood samples were obtained from a finger prick using aseptic technique; haemoglobin concentrations were measured immediately with a portable battery-operator Hemocue B-Haemoglobin photometer (Hemocue Inc., Angelholm, Sweden) by trained technicians [31], who were unaware of the allocation of micronutrient supplement. Anaemia was defined as a haemoglobin concentration below $110 \mathrm{~g} / \mathrm{L}$.

\section{Anthropometric measurement}

The height and weight of the infants and children were measured every 4 weeks during the 24-week intervention. A calibrated SECA scale with intervals of $0.1 \mathrm{~kg}$ was used to measure weight. An infant length board with a sliding foot board was used to measure the recumbent length to the nearest $0.1 \mathrm{~cm}$ of children less than 24 months, and a wooden scale with a sliding head piece was used to measure the standing height of children 24 months and older. Two field workers, who were unaware of which group a child belonged to, completed the measurements in duplicate using standardized WHO procedures[32]. Height for age, weight for age, and weight for height Z-scores were calculated using the WHO Child Growth Standard (WHO Anthro software, version 3.01) [33].

\section{Training of village health volunteers}

A total of 16 VHVs were recruited and given a 1-day training session before the initiation of the study. The benefits, adverse side effects, usage of the MMP supplement (food demonstration), MMP supplement nutrition education and instructions on follow-up using the monitoring form were all explained. The VHVs delivered MMP supplements to the intervention groups on a weekly basis and instructed the mothers on how to administer the dose in a single meal, twice weekly for one group (the TWS group) and daily for the other (the DS group). To ensure that children consumed the entire dose, mothers were asked to mix the MMP supplement with a small amount of the child's food just before consumption.

\section{Monitoring forms (compliance and acceptability)}

The VHVs used monitoring forms to record the number of MMP sachets consumed by the children in the two intervention groups, any side effects, and any illnesses that occurred during the study period. For the TWS group, a VHV visited the house every Monday providing one sachet and every Friday giving the other sachet. For the DS group, VHVs visited the house every Monday and provided all seven sachets. The sachets left unconsumed from the previous week were counted on the next Monday's visit. The three health centre nurses collected the monitoring forms weekly from the 16 VHVs. All monitoring forms were checked by the NIOPH supervisor and reviewed by the main researcher on a monthly basis. The total number of empty sachets was used to measure compliance. For the TWS group, good compliance was defined as when children consumed more than $70 \%$ of all the MMP sachets provided, and for the DS group when at least five sachets of the MMP supplements provided per week were consumed during the 24 weeks of the study.

\section{Statistical analysis}

Data were analysed using the PASW statistical package, version 18.0 (SPSS Inc., Chicago, IL, USA). Socio-demographic, health, and nutrition characteristics of the study subjects were summarised as mean and standard deviation (SD) for continuous variables and as frequency for categorical variables. Differences in prevalence were tested with the Pearson chi-squared test. Differences in mean haemoglobin concentration and Z-scores between the groups at the beginning and at the end of the intervention were examined using Repeated Measures Analysis of Variance. The McNemar test was used to assess within group differences at three time points in the study subjects with anaemia and one-way ANOVA was used to assess changes in mean haemoglobin concentration in the treatment groups. All the analyses were carried out for all subjects and separately for the children who were anaemic at baseline. Values of $p<0.05$ were considered to be significant for all tests. 


\section{Results}

Of the 336 children recruited, five (1.5\%) were lost to follow-up before the 12-week assessment (three moved out of the study area, and two developed diarrhoea and their mothers refused to continue the study). Thus 331 study subjects completed all 24 weeks of the trial (Figure 1).

\section{Baseline characteristics}

Baseline information (Table 1) revealed some typical characteristics of population in the rural communities of Lao PDR. The majority of study subjects had mothers with relatively low levels of education and were from households with low access to basic facilities such as improved water sources and latrines. The nutritional status of the study subjects was characterized by a relatively high prevalence of both stunting and underweight. There were no significant differences between the groups in terms of sex distribution, mean age, weight, and height.
Although it was unintended, the haemoglobin concentration was significantly different at baseline in the control $(\mathrm{n}=110)$ compared with in the two supplementation groups. Children in the control group had, on average, a higher mean haemoglobin concentration and thus a lower incidence of anaemia compared with the children in the two supplementation groups.

\section{Effects of the intervention}

Overall, the prevalence of anaemia decreased from $58.6 \%$ to $26.1 \%$ in the TWS group and from $53.6 \%$ to $18.2 \%$ in DS group over the 24 -week study period. Decrease in prevalence was also observed in the control group, from $34.5 \%$ to $23.6 \%$; however, the change was significant only between weeks 12 and 24, whereas in the TWS and DS groups the changes were significant between the baseline and week 12 and between weeks 12 and 24. Thus, anaemia prevalence in the DS group was reduced by $35.4 \%$ in the 6 months compared with $32.5 \%$ in the TWS group $(p=0.043)$ and $10.9 \%(p$

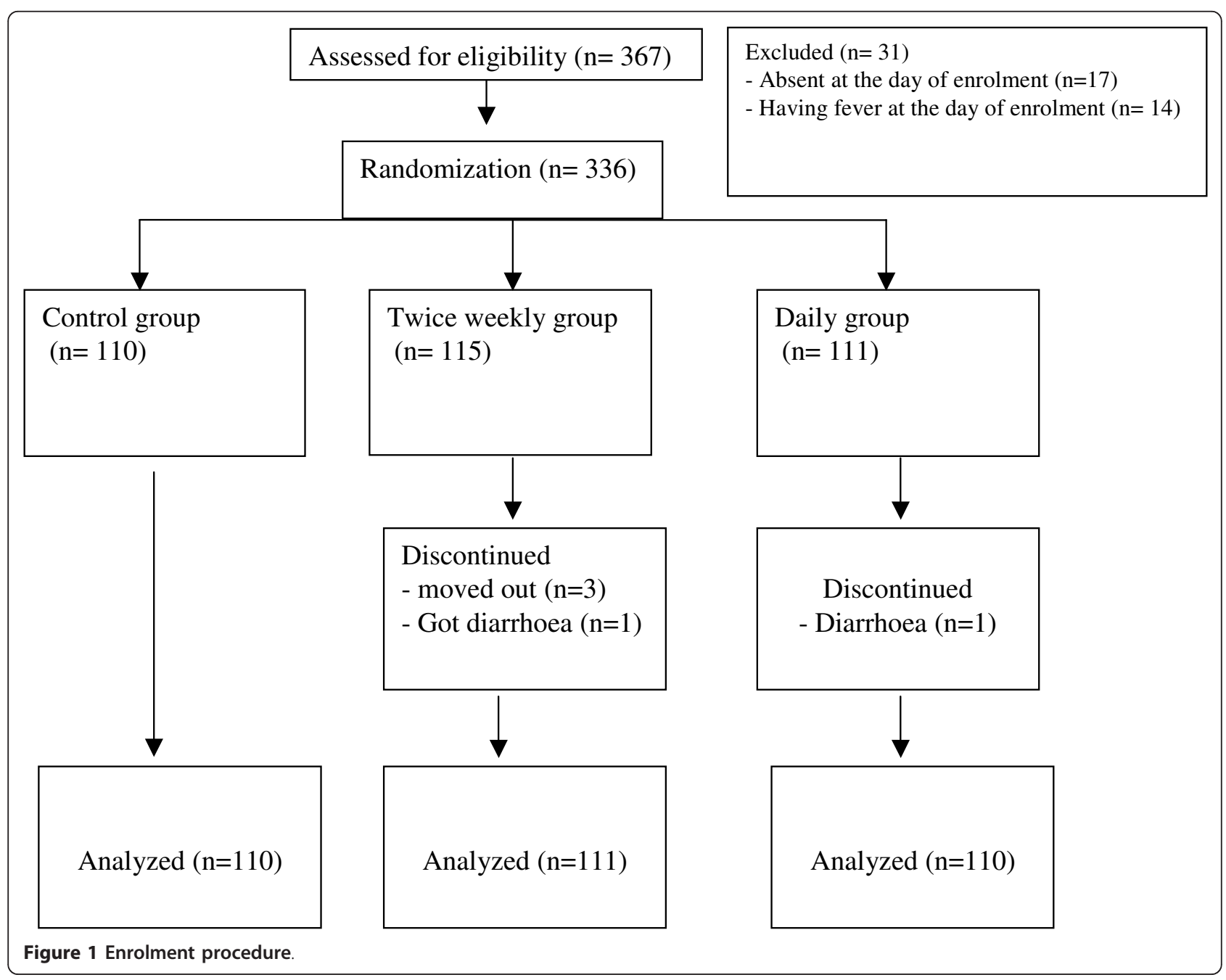


Table 1 Baseline characteristics of the control, daily supplementation, and twice weekly supplementation groups

\begin{tabular}{|c|c|c|c|c|}
\hline & $\begin{array}{r}\text { Control } \\
(n=110)\end{array}$ & $\begin{array}{r}\text { Twice weekly } \\
(\mathrm{n}=111)\end{array}$ & $\begin{array}{r}\text { Daily } \\
(n=110)\end{array}$ & $P^{1}$ \\
\hline Age, months & $31.1 \pm 14.6^{\mathrm{a}}$ & $32.4 \pm 14.6$ & $32.0 \pm 13.3$ & 0.793 \\
\hline Sex, male $[\%]$ & 34.5 & 46.8 & 42.7 & 0.168 \\
\hline Maternal age, year & $28.4 \pm 6.8$ & $29.5 \pm 8.4$ & $29.0 \pm 7.1$ & 0.583 \\
\hline Maternal education, year & $6.74 \pm 3.1$ & $6.38 \pm 3.2$ & $6.35 \pm 3.6$ & 0.637 \\
\hline Mothers working outside [\% ] & 93.6 & 84.7 & 90.9 & 0.080 \\
\hline High SES $2 \%)]$ & 31.8 & 30.6 & 31.8 & 0.976 \\
\hline Household having > 6 members [\% ] & 49.1 & 49.5 & 58.2 & 0.314 \\
\hline Breastfeed infants[\%] & 33.6 & 23.4 & 20.9 & 0.074 \\
\hline Commercial baby formula [\%] & 19.1 & 13.5 & 19.1 & 0.473 \\
\hline Complementary food: Rice [\%] & 60.9 & 59.5 & 58.2 & 0.473 \\
\hline Meat [\%(] & 77.3 & 64.9 & 61.8 & 0.034 \\
\hline Egg [\%(] & 50.0 & 57.7 & 53.6 & 0.521 \\
\hline Haemoglobin concentration, g/L & $114.3 \pm 15.2$ & $105.1 \pm 13.3$ & $107.1 \pm 13.0$ & $<0.001$ \\
\hline Anaemia, [\% ] & 34.5 & 58.6 & 53.6 & $<0.001$ \\
\hline Weight, kg & $11.0 \pm 2.5$ & $11.3 \pm 2.5$ & $11.3 \pm 2.5$ & 0.637 \\
\hline Height, $\mathrm{cm}$ & $84.2 \pm 10.6$ & $85.9 \pm 10.8$ & $85.6 \pm 10.4$ & 0.441 \\
\hline Weight-for-height Z-score & $-0.48 \pm 1.01$ & $-0.63 \pm 1.12$ & $-0.53 \pm 0.98$ & 0.544 \\
\hline Height-for-age Z-score & $-1.84 \pm 1.62$ & $-1.65 \pm 1.70$ & $-1.73 \pm 1.53$ & 0.677 \\
\hline Weight-for-age Z-score & $-1.38 \pm 1.13$ & $-1.38 \pm 1.16$ & $-1.36 \pm 1.10$ & 0.990 \\
\hline Wasting $^{3}[\%$ & 4.5 & 9.9 & 7.3 & 0.307 \\
\hline Stunting ${ }^{4}[\%]$ & 44.5 & 42.3 & 40.4 & 0.792 \\
\hline Underweight ${ }^{5}[\%]$ & 27.3 & 30.6 & 27.3 & 0.815 \\
\hline
\end{tabular}

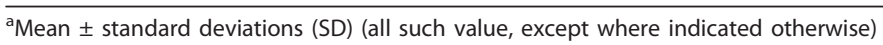

${ }^{1}$ Based on ANOVA (continuous variables) or Chi-square tests (categorical variables)

2 Socio-economic status "high" is defined as household with electricity, improved water source and latrine and "low" is lacking one or all of these.

${ }^{3}$ Wasting: Percentage below -2 standard deviations (SD) for weight-for-length/height Z-scores based on WHO child growth standard

${ }^{4}$ Stunting: Percentage below -2 standard deviations (SD) for length/height-for-age Z-scores based on WHO child growth standard

${ }^{5}$ Underweight: Percentage below -2 standard deviations (SD) for weight-for-age Z-scores based on WHO child growth standard

$<0.001)$ in the control group. To eliminate the effect of the initial difference in anaemia prevalence, we grouped the subjects who were anaemic separately from those who were not anaemic at baseline and compared the change in prevalence (Table 2). Of the children who were anaemic at baseline, the proportion that remained anaemic decreased most rapidly in the DS group: to $59.3 \%$ by week 12 and to $32.2 \%$ by week 24 . The decrease in anaemia prevalence was lower in the TWS group (44.6\% by week 24$)$ and lowest in the control group (65.8\% at week 24). By week 12, the proportion of anaemic children was significantly different between the control and DS groups and, by week 24, the proportion in the two intervention groups was significantly lower than in the control group. Although some children in the control and DS groups who were non-anaemic at baseline became anaemic in the early stages of the study, all but two of them were non-anaemic by week 24.

\section{Haemoglobin concentration}

During the whole study period, the mean haemoglobin concentration increased from $107.1 \mathrm{~g} / \mathrm{L} \pm 13.0 \mathrm{~g} / \mathrm{L}(\mathrm{SD})$ to $120.0 \mathrm{~g} / \mathrm{L} \pm 11.6(\mathrm{SD}) \mathrm{g} / \mathrm{L}$ in the DS group, and from

Table 2 Number (percentage) of children with anaemia at Week 12 and Week 24 of supplementation by treatment groups

\begin{tabular}{|c|c|c|c|c|c|c|}
\hline & \multicolumn{3}{|c|}{ Non-anaemic at baseline } & \multicolumn{3}{|c|}{ Anaemic at baseline } \\
\hline & $\begin{array}{l}\text { Control } \\
(\mathrm{N}=72)\end{array}$ & $\begin{array}{c}\text { Twice weekly } \\
(\mathrm{N}=46)\end{array}$ & $\begin{array}{c}\text { Daily } \\
(\mathrm{N}=51)\end{array}$ & $\begin{array}{l}\text { Control } \\
(\mathrm{N}=38)\end{array}$ & $\begin{array}{l}\text { Twice weekly } \\
(\mathrm{N}=65)\end{array}$ & $\begin{array}{c}\text { Daily } \\
(N=59)\end{array}$ \\
\hline Week 12 & $3(4.2 \%)^{\mathrm{A}}$ & $0(0.0 \%)^{A}$ & $6(11.8 \%)^{\mathrm{B}}$ & $32(84.2 \%)^{\mathrm{A}}$ & $48(73.8 \%)^{\mathrm{A}}$ & $35(59.3 \%)^{B}$ \\
\hline Week 24 & $1(1.4 \%)$ & $0(0.0 \%)$ & $1(2.0 \%)$ & $25(65.8 \%)^{\mathrm{A}}$ & $29(44.6 \%)^{B}$ & $19(32.2 \%)^{\mathrm{B}}$ \\
\hline
\end{tabular}

\footnotetext{
A, B Within each class of anaemic status at baseline, groups with different letters have significant differences $($ McNemar Test, $\mathrm{P}<0.05)$.
} 
$105.1 \mathrm{~g} / \mathrm{L} \pm 13.3 \mathrm{~g} / \mathrm{L}(\mathrm{SD})$ to $118.0 \pm 13.9 \mathrm{~g} / \mathrm{L}(\mathrm{SD})$ in the TWS group. In the control group, the change in haemoglobin concentration was smaller, from $114.3 \mathrm{~g} / \mathrm{L}$ $\pm 13.0 \mathrm{~g} / \mathrm{L}(\mathrm{SD})$ to $117.4 \pm 12.8 \mathrm{~g} / \mathrm{L}(\mathrm{SD})$. Again, to eliminate the effects of the initial differences among groups, we separated the children by the haemoglobin concentration at baseline into non-anaemic $(\mathrm{Hb}>110.0$ g/L), mildly anaemic (Hb 100.0-109.0 g/L), and severely to moderately anaemic $(\mathrm{Hb}<100.0 \mathrm{~g} / \mathrm{L})$.

By week 12, the children in both the TWS and DS groups who were non-anaemic or mildly anaemic at baseline showed similar increases in haemoglobin concentration and this was significantly greater than for the non-anaemic or mildly anaemic children in the control group (Figure 2). However, for the severely to moderately anaemic children at baseline, the increase in haemoglobin concentration was greater in the DS group compared with in the TWS or control groups (Figure 2). The change in haemoglobin concentration by week 24 showed a similar trend; however, the differences between the groups were not significant because of the large variance in the control and TWS groups (Figure 3).

\section{Anthropometric measures}

The anthropometric Z-scores for the three groups are shown in Table 3. Overall, the Z-scores of height for age increased, the Z-scores of weight for age showed no major improvements, and the weight for height Z-scores decreased in all groups. The increase in height for age Z-scores and the decrease in weight for height Z-scores were significantly greater in the control and DS groups than in the TWS groups.

\section{Compliance and acceptability}

All children in TWS group consumed two sachets of sprinkles per week, giving $100.0 \%$ compliance for this group. In the DS group, $72.7 \%$ of children consumed five or more sachets of MMP per week and $43.6 \%$ of the children consumed all seven sachets per week for all 24 weeks. The most common reason for not taking powder in the DS group was illness, such as diarrhoea $(\mathrm{n}=20)$, cough $(\mathrm{n}=$ $10)$ and forgetting to take supplements $(n=32)$.

The monitoring reports showed that mothers of the children in both the intervention groups reported that their children had constipation or dark stool. There was no significant difference in reports of illness (diarrhoea or cough) between the control, DS and TWS groups (32.7\%, $39.1 \%$, and $34.2 \%$, respectively; $p=0.587), 42.1 \%(93 / 221)$ of mothers reported that sprinkles changed the colour of their children's food and 43.9\% (97/221) reported that sprinkles had an unpleasant smell or taste. Some mothers mixed the sprinkles in liquids such as juice or milk. Many of the mothers felt the MMP had increased their child's appetite (31.7\%) and playfulness (48.4\%).

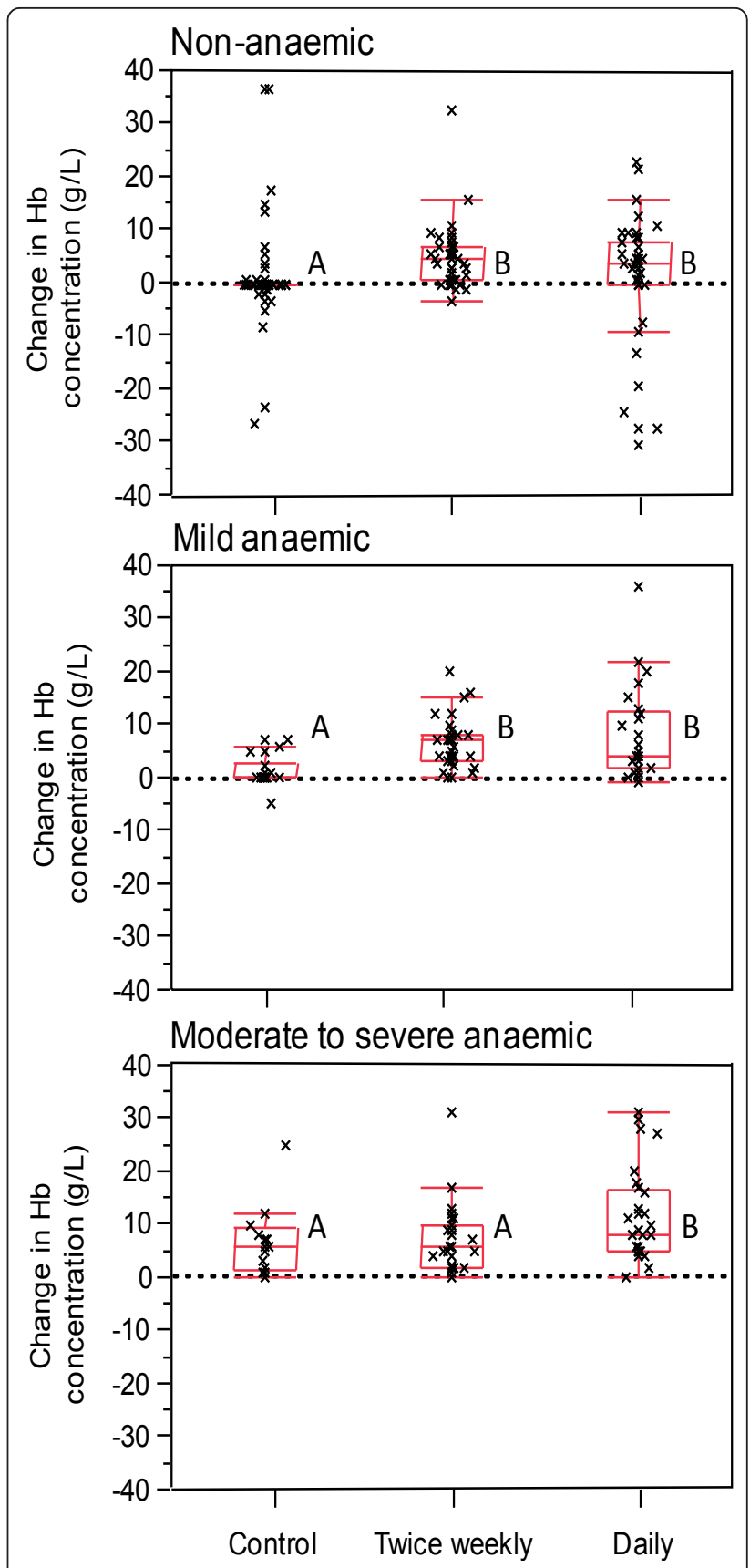

Figure 2 Change in haemoglobin concentration from Week 0 to Week 12 in children who were non-anaemic (haemoglobin concentration $\geq 110 \mathrm{~g} / \mathrm{L})$, mild anaemic (100-109 g/L), and moderate to severe anaemic $(<100 \mathrm{~g} / \mathrm{L})$ at Week 0 . The box indicates the range of the 1 st to 3 rd quartile with central line at median; Vertical bars indicate the 1.5 times inter-quartile range outside 1st and 3rd quartiles. Within each panel, groups with different letters have significant difference (Mann Whitney $U$ test, $P<0.05$ ).

\section{Discussion}

This randomized controlled trial was used to compare the effect of taking two sachets of MMP supplementation per week with taking a daily sachet in reducing 


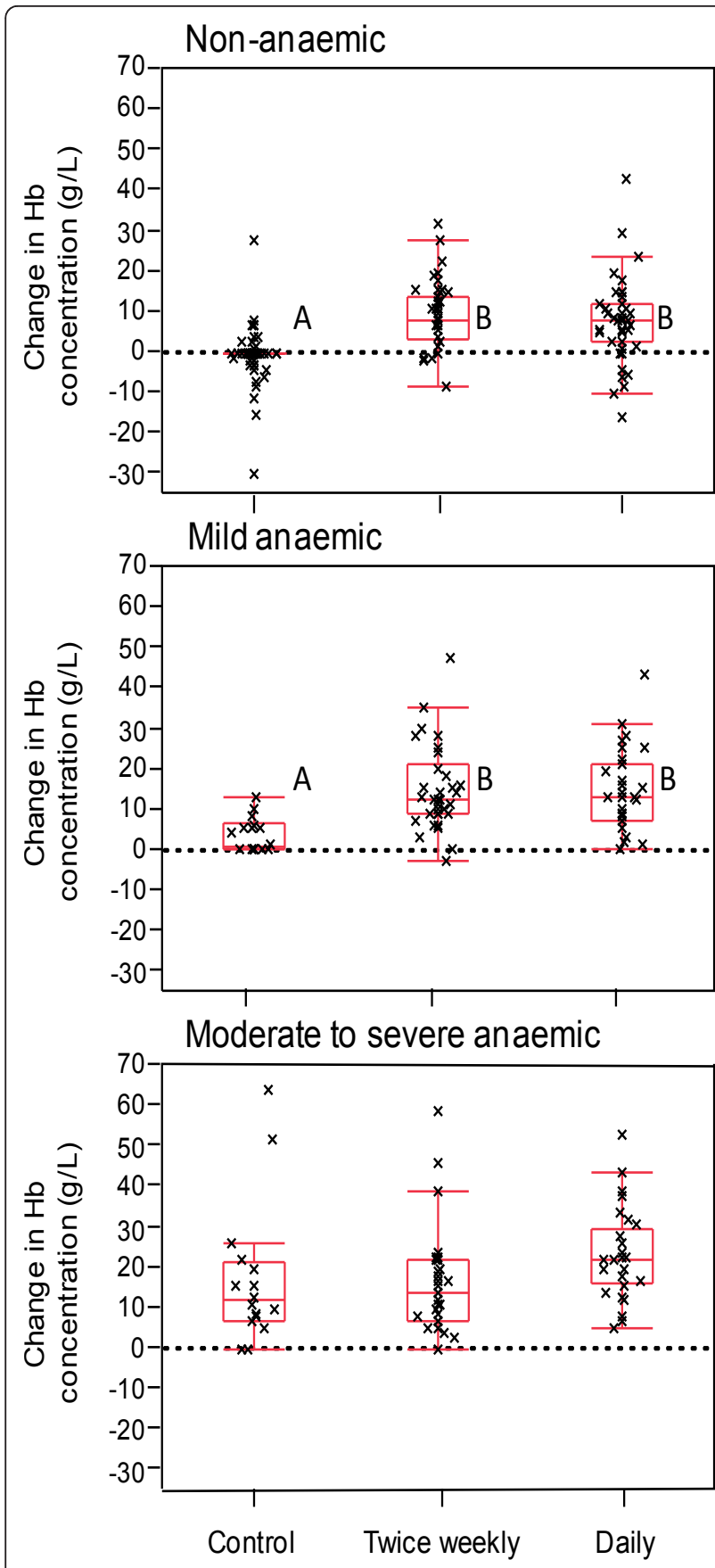

Figure 3 Change in haemoglobin concentration from Week 0 to Week 24 in children who were non-anaemic (haemoglobin concentration $\geq 110 \mathrm{~g} / \mathrm{L}$ ), mild anaemic (100-109 g/L), and moderate to severe anaemic $(<100 \mathrm{~g} / \mathrm{L})$ at Week 0 . The box indicates the range of the 1 st to 3 rd quartile with central line at median; Vertical bars indicate the 1.5 times inter-quartile range outside 1st and 3rd quartiles. Within each panel, groups with different letters have significant difference (Mann Whitney $U$ test, $\mathrm{P}$ $<0.05)$. anaemia prevalence and in improving haemoglobin concentration and growth among 331 infants and young children in rural communities of Lao PDR. The study showed that MMP supplementation was effective in reducing anaemia prevalence and in improving haemoglobin concentration in both treatment groups. This result agrees with the results of previous studies in several developing countries [17-25].

Overall, this study showed that the use of either two sachets per week or a daily sachet of MMP supplements resulted in similar increases in haemoglobin concentration and similar reductions in anaemia prevalence. This result supports similar studies in Vietnam [28], Indonesia [34] and Bangladesh[35]. We found that for severely to moderately anaemic children, daily supplementation of MMP was more effective in reducing anaemia prevalence and in improving haemoglobin concentration than TWS. This supports the results of many other micronutrients supplementation trials that suggest that daily micronutrient supplement was the best treatment for improving both anaemia and haemoglobin concentration [36-38]. The reduction of anaemia was also observed in the control group, but the reduction was relatively smaller than in the DS and TWS groups. The average increase in haemoglobin concentration in the DS and TWS groups was 18.6 and $15.6 \mathrm{~g} / \mathrm{L}$, respectively, higher than in the control group, for which the average increase was $9.3 \mathrm{~g} / \mathrm{L}(p<0.001)$.

Several studies have shown that weekly iron supplementation, either alone or with other micronutrients, is as effective as daily iron supplementation in reducing anaemia in children $[28,34]$. Other studies have indicated that daily iron supplementation is more efficient [39-41]. However, daily multiple micronutrients supplementation should be better than daily iron alone for controlling anaemia, because anaemia is not caused by iron deficiency alone but by the lack of other micronutrients, such as riboflavin, folic acid, vitamin $\mathrm{C}$, and vita$\min \mathrm{A}$, that are known to favour iron absorption and/or haematopoiesis $[42,43]$.

The DS group received $70 \mathrm{mg}$ of iron every week, whereas the TWS group received $20 \mathrm{mg}$ of iron in a week. Over the 24 weeks of the trial, $43.6 \%$ of the DS group received 1,680 $\mathrm{mg}$ of iron (168 sachets $\times 10 \mathrm{mg}$ ), and $27.3 \%$ of the DS group received $960 \mathrm{mg}$ of iron (96 sachets $\times 10 \mathrm{mg}$ ). This amount should be sufficient to produce a haemoglobin response. The amount of iron recommended by the Sprinkles Global Health Initiative for preventing anaemia among children under five years of age is $600 \mathrm{mg}$. The DS and TWS groups both showed a significant dose-response. If a daily dose of MMP was 
Table 3 Change in anthropometric measurements in the three groups during the study period.

\begin{tabular}{llcccc}
\hline & & $\begin{array}{c}\text { Control } \\
(\mathbf{n}=\mathbf{1 1 0})\end{array}$ & $\begin{array}{c}\text { Twice-weekly } \\
\mathbf{( n = 1 1 1 )}\end{array}$ & $\begin{array}{c}\text { Daily } \\
(\mathbf{n}=\mathbf{1 1 0})\end{array}$ \\
\hline Weight for height Z score & Baseline & $-0.48 \pm 1.01^{\mathrm{a}}$ & $-0.63 \pm 1.12$ & $-0.53 \pm 0.98$ & 0.544 \\
& Week 24 & $-1.09 \pm 1.08$ & $-0.97 \pm 1.06$ & $-1.15 \pm 1.04$ & 0.414 \\
Height for age Z score & Change & $-0.61 \pm 0.96^{\mathrm{A}}$ & $-0.33 \pm 0.97^{\mathrm{B}}$ & $-0.62^{\mathbf{b}} \pm 0.84^{\mathrm{A}}$ & 0.036 \\
& Baseline & $-1.84 \pm 1.62$ & $-1.65 \pm 1.70$ & $-1.73 \pm 1.53$ & 0.677 \\
Weight for age Z score & Week 24 & $-0.89 \pm 1.56$ & $-1.00 \pm 1.49$ & $-0.77 \pm 1.41$ & 0.532 \\
& Change & $0.95 \pm 0.97^{\mathrm{A}}$ & $0.65 \pm 0.93^{\mathrm{B}}$ & $0.95 \pm 0.99^{\mathrm{A}}$ & 0.029 \\
& Baseline & $-1.38 \pm 1.13$ & $-1.38 \pm 1.16$ & $-1.36 \pm 1.10$ & 0.990 \\
& Week 24 & $-1.27 \pm 1.08$ & $-1.24 \pm 1.10$ & $-1.23 \pm 0.93$ & 0.969 \\
\hline
\end{tabular}

a Mean \pm SD (all such value, except where indicated otherwise)

${ }^{b}$ Analysis of variance;

A, B Differences between groups are significant when letters are different ( $t$ test, $P<0.05$ ).

used with full compliance, it should have been possible to eliminate anaemia in the study subjects during the 6 months of trial.

The positive effects of iron [44,45], vitamin A[46], and zinc [47] on child growth have been reported. Some studies have found that supplementation with multiple micronutrients had a positive effect on length gain, whereas in others, either weight gain improved or there was no effect[48]. We observed that inadequate breastfeeding and weaning practices might contribute to high rates of malnutrition among study subjects as for general population in these age groups. Although the young children (age less than 24 months), 39.1\% were already stunted. This high rate of stunting was similar to the prevalence found among children from the same age group in a 2006 national nutrition survey [13]. Overall, during the supplementation period an improvement was observed in height-for-age $\mathrm{Z}$ scores among three groups, but the effect of MMP was unclear. This may not be related with MMP supplementation because the change in height-for-age was smaller in TWS group, but children in the daily group were similar to the control group. The decrease in weight for height $\mathrm{Z}$ scores might be because of the episodes of morbidity among study subjects during the study period. Acute episodes of morbidity might have direct and immediate impact on weight than on height. Secondly, the lack of effect of MMP on weight may have been because the complementary foods consumed by the children were inadequate in energy; no additional complementary foods were provided to the families. Thirdly, it might be related to timing. If the trial period coincides with the period of dietary transition when the diet becomes more qualitatively deficient than quantitatively deficient, the results may be compromised [49].

This study design had some limitations: (i) the anaemic children were not equally distributed among the groups; (ii) the different number of home visits for the two intervention groups may have influenced the amount of attention given to feeding practices and compliance; (iii) because of financial and technical constraints in the Lao context, it was not possible to provide a mask to the mothers or to the field workers who delivered the MMP sprinkles. However, the strength of the study is in its low dropout rate (1.5\%).

The results of this trial are of relevance beyond the immediate study zone, because the nutritional status of the children in the study is similar to that of most of the children in Lao PDR. The proportion of children in the study who had stunted growth was $40.2 \%$, and this compares well with the proportion of preschool children (40.4\%) reported to have stunted growth for Lao PDR overall. Anaemia was more common in the study subjects $(48.9 \%)$ compared with the national estimated anaemia prevalence of $41 \%$ in pre-school children [13].

This study indicates that the home fortification of complementary foods with multiple micronutrient supplements is an effective choice for reducing the prevalence of anaemia in children living in a setting where locally available iron-rich foods may not be affordable or accessible. The children in remote areas of Lao PDR would potentially benefit if sprinkles were incorporated into the current outreach program of the primary health care services, especially if implemented in combination with a social advocacy strategy to encourage their use to prevent anaemia. Over a longer term, health education that aims to modify food habits would be necessary to improve child growth rates.

\section{Conclusions}

The results of this trial suggest that daily MMP supplementation produced the best result in terms of anaemia reduction. However, the results are insufficient to make recommendations to the Ministry of Health authorities 
about which supplementation scheme will be most appropriate to treat anaemia and multiple micronutrient deficiencies during infancy. The results are inconclusive because even in the DS group, the group for which the intervention was most effective, $32.2 \%$ of the subjects remained anaemic at the end of the trial. This study indicates that, in addition to supplementation with MMP sprinkles, long-term educational intervention to promote healthy weaning practices and the consumption of nutritionally complementary foods is necessary.

\section{Ethical approval}

Ethical approval for this study was obtained from the Nagasaki University Ethical Review Board (Japan) and the National Ethic Committee for Health Research of the Ministry of Health (Lao PDR). A parent or guardian for all children participating in the study provided written informed consent.

\begin{abstract}
Acknowledgements
We would like to extend a very sincere thanks to the Director General of the Hygiene and Prevention Department (HPD), MOH, Lao PDR; Director General of the Savannakheth Provincial Health Department, the Director of the Savannakheth Provincial Malaria Station, the Directors of Songkhone District Hospital, the authorities from six studied villages, all six nurses from the Lahanam health centre, and 16 village health volunteers; and Dr. Khouanchai Soundavong for her field supervision. Special thanks go to all of the mothers/caretakers of the children who voluntarily participated in this study. This study was conducted as a part of the Eco-Health Project of the Research Institute for Humanity and Nature, Kyoto (Japan), in collaboration with the National Institute of Public Health, Ministry of Health $(\mathrm{MOH})$ of Lao People's Democratic Republic. MMP supplements were provided by UNICEF through HPD of MOH, Lao PDR. SK was in receipt of Asian Health \& Education Fund, Tokyo (Japan), and partial receipt of the Institute of Tropical Medicine, Nagasaki University (NEKKEN) Fellowship.

\section{Author details}

${ }^{1}$ National Institute of Public Health, Ministry of Health, Vientiane, Lao People's Democratic Republic. ${ }^{2}$ Department of International Health, Institute of Tropical Medicine (NEKKEN) and the Global Centre of Excellence Program (GCOE), Nagasaki University, Japan. ${ }^{3}$ Division of Biological Anthropology, Department of Archaeology and Anthropology, University of Cambridge, United Kingdom. ${ }^{4}$ Research Institute for Humanity and Nature, Kyoto, Japan.
\end{abstract}

\section{Authors' contributions}

SK conceived of the study; NM-T, SK, TS, MH, TY, KM, and BB designed the study; SK carried out the field work; SK, TS, MH and NM-T analysed the data; NM-T, SK, TS, MH, TY, KM, and BB interpreted the data; SK and TS drafted the manuscript; $\mathrm{MH}, J \mathrm{O}, \mathrm{TY}, \mathrm{KM}, \mathrm{NM}-\mathrm{T}$, and $\mathrm{BB}$ revised the manuscript. All authors read and approved the final manuscript.

\section{Competing interests}

The authors declare that they have no competing interests.

Received: 1 March 2011 Accepted: 24 November 2011 Published: 24 November 2011

\section{References}

1. WHO/WFP/UNICEF: Preventing and Controlling Micronutrient Deficiencies in Population Affected by an Emergency: Multiple vitamins and minerals supplements for pregnant and lactating women, and for children aged 6-59 mo. Joint statement by the WHO/WFP/UNICEF WHO Geneva 2007.

2. Kikafunda JK, Walker AF, Collett D, Tumwine JK: Risk factors for early childhood malnutrition in Uganda. Pediatrics 1998, 102(4):E45.
3. Vazir S, Naidu AN, Vidyasagar P: Nutritional status, psychosocial development and the home environment of Indian rural children. Indian Pediatr 1998, 35(10):959-966.

4. Idjradinata P, Pollitt E: Reversal of developmental delays in iron-deficient anaemic infants treated with iron. Lancet 1993, 341(8836):1-4

5. Rahmathullah L, Underwood BA, Thulasiraj RD, Milton RC, Ramaswamy K, Rahmathullah R, Babu G: Reduced mortality among children in southern India receiving a small weekly dose of vitamin A. N Engl J Med 1990, 323(14):929-935.

6. Brown KH, Peerson JM, Allen LH: Effect of zinc supplementation on children's growth: a meta-analysis of intervention trials. Bibl Nutr Dieta 1998, 54:76-83.

7. Castillo-Duran C, Rodriguez A, Venegas G, Alvarez P, Icaza G: Zinc supplementation and growth of infants born small for gestational age. $J$ Pediatr 1995, 127(2):206-211.

8. Umeta M, West CE, Haidar J, Deurenberg P, Hautvast JG: Zinc supplementation and stunted infants in Ethiopia: a randomised controlled trial. Lancet 2000, 355(9220):2021-2026.

9. de Pee S: Need, Efficacy, and Effectiveness of Multiple Vitamin/Mineral Supplements for Young Children and Considerations for Programs. In Nutrition and Health in Developing Countries.. second edition. Edited by: Richard D Semba, Martin W Bloem. Humana Press. Totowa, NJ; 2008:

10. Gibson RS, Ferguson EL, Lehrfeld J: Complementary foods for infants feeding in developing countries: Their nutrient adequacy and improvement. Eur J Clin Nutr 1998, 52:764-770.

11. Allen LH: Causes of nutrition-related public health problems of preschool children: available diet. J Pediatr Gastroenterol Nutr 2006, 43(Suppl 3):S8-12.

12. Miyoshi M, Phommasack B, Nakamura S, Kuroiwa C: Nutritional status of children in rural Lao PDR: who are the most vulnerable? Eur J Clin Nutr 2005, 59(7):887-890.

13. NSC: Monitoring the situation of children and women: Multiple Indicators Cluster Survey and National Nutrition Survey. UNICEF/MOH/ MPI Lao PDR. 2006. Final Report 2006.

14. UNICEF/UNU/WHO: Iron deficiency anemia: assessment, prevention, and control. A guide for programme managers. WHO/NIID [Report no013] 2001.

15. Barennes H, Simmala C, Odermatt P, Thaybouavone T, Vallee J, MartinezAussel B, Newton PN, Strobel M: Postpartum traditions and nutrition practices among urban Lao women and their infants in Vientiane, Lao PDR. Eur J Clin Nutr 2009, 63(3):323-331.

16. Zlotkin S, Antwi KY, Schauer C, Yeung G: Use of microencapsulated iron(II) fumarate sprinkles to prevent recurrence of anaemia in infants and young children at high risk. Bull World Health Organ 2003, 81(2):108-115.

17. Hirve S, Bhave S, Bavdekar A, Naik S, Pandit A, Schauer C, Christofides A, Hyder Z, Zlotkin S: Low dose 'Sprinkles'- an innovative approach to treat iron deficiency anemia in infants and young children. Indian Pediatr 2007, 44(2):91-100.

18. Adu-Afarwuah S, Lartey A, Brown KH, Zlotkin S, Briend A, Dewey KG: Home fortification of complementary foods with micronutrient supplements is well accepted and has positive effects on infant iron status in Ghana. Am J Clin Nutr 2008, 87(4):929-938.

19. Menon P, Ruel MT, Loechl CU, Arimond M, Habicht JP, Pelto G, Michaud L: Micronutrient Sprinkles reduce anemia among 9- to 24-mo-old children when delivered through an integrated health and nutrition program in rural Haiti. J Nutr 2007, 137(4):1023-1030.

20. Zlotkin S, Arthur P, Antwi KY, Yeung G: Treatment of anemia with microencapsulated ferrous fumarate plus ascorbic acid supplied as sprinkles to complementary (weaning) foods. Am J Clin Nutr 2001, 74(6):791-795.

21. Zlotkin S, Arthur P, Schauer C, Antwi KY, Yeung G, Piekarz A: Homefortification with iron and zinc sprinkles or iron sprinkles alone successfully treats anemia in infants and young children. J Nutr 2003, 133(4):1075-1080.

22. Christofides A, Asante KP, Schauer C, Sharieff W, Owusu-Agyei S, Zlotkin S: Multi-micronutrient Sprinkles including a low dose of iron provided as microencapsulated ferrous fumarate improves haematologic indices in anaemic children: a randomized clinical trial. Matern Child Nutr 2006, 2(3):169-180.

23. Giovannini M, Sala D, Usuelli M, Livio L, Francescato G, Braga M, Radaelli G, Riva E: Double-blind, placebo-controlled trial comparing effects of supplementation with two different combinations of micronutrients 
delivered as sprinkles on growth, anemia, and iron deficiency in cambodian infants. J Pediatr Gastroenterol Nutr 2006, 42(3):306-312.

24. Zlotkin SH, Schauer C, Christofides A, Sharieff W, Tondeur MC, Hyder SM: Micronutrient sprinkles to control childhood anaemia. PLoS Med 2005, 2(1):e1.

25. Zlotkin SH, Christofides AL, Hyder SM, Schauer CS, Tondeur MC, Sharieff W Controlling iron deficiency anemia through the use of home-fortified complementary foods. Indian J Pediatr 2004, 71(11):1015-1019.

26. Zlotkin S: Micronutrient sprinkles for use in infants and young children: guidelines on recommendations for use and program monitoring and evaluation. Sprinkles Global Health Initiative 2008.

27. Mora JO: Iron supplementation: overcoming technical and practical barriers. J Nutr 2002, 132(4 Suppl):853S-855S.

28. Thu BD, Schultink W, Dillon D, Gross R, Leswara ND, Khoi HH: Effect of daily and weekly micronutrient supplementation on micronutrient deficiencies and growth in young Vietnamese children. Am J Clin Nutr 1999, 69(1):80-86.

29. Murayama N, Natsuhara K, Sasaki S, Kounnavong S, Phonglusa K, Sithideth D: Dietary intake and indicators of dietary change in Lahanam, Savannakhet, Lao People's Democratic Republic in Health Development Study in Lahanam, Savannakhet, Lao P.D.R. April 2004 to March 2006 Project Report 2006.

30. Drewett R, Amatayakul K, Wongsawasdii L, Mangklabruks A, Ruckpaopunt S, Ruangyuttikarn C, Baum D, Imong S, Jackson D, Woolridge M: Nursing frequency and the energy intake from breast milk and supplementary food in a rural Thai population: a longitudinal study. Eur J Clin Nutr 1993, 47(12):880-891.

31. Cohen ARS-FJ: HemoCue system for haemoglobin measurement. Evaluation in anaemic and non-anaemic children. Am J Clin Pathol 1988, 90:302-305.

32. de Onis M, Onyango AW, Van den Broeck J, Chumlea WC, R M: The WHO Multicentre Growth Reference Study Group. Measurement and standardization protocols for anthropometry used in the construction of a new international growth reference. Food and Nutrition Bulletin 2004, 25(Supplement1):S27-36.

33. WHO: WHO Anthro for personal computers, version 3.01: Software for assessing growth and development of the world's children. 2009.

34. Schultink W, Gross R, Gliwitzki M, Karyadi D, Matulessi P: Effect of daily vs twice weekly iron supplementation in Indonesian preschool children with low iron status. Am J Clin Nutr 1995, 61(1):111-115.

35. Hyder SMZ, Haseen F, Rahman M, Tondeur MC, aZS H: Effect of daily versus once-weekly home fortification with micronutrient Sprinkles on hemoglobin and iron status among young children in rural Bangladesh. Food and Nutrition Bulletin 2007, 28(2):156-164.

36. Smuts CM, Dhansay MA, Faber M, van Stuijvenberg ME, Swanevelder $S$, Gross R, Benade AJ: Efficacy of multiple micronutrient supplementation for improving anemia, micronutrient status, and growth in South African infants. J Nutr 2005, 135(3):653S-659S.

37. Untoro J, Karyadi E, Wibowo L, Erhardt MW, Gross R: Multiple micronutrient supplements improve micronutrient status and anemia but not growth and morbidity of Indonesian infants: a randomized, double-blind, placebo-controlled trial. J Nutr 2005, 135(3):639S-645S

38. Wijaya-Erhardt M, Erhardt JG, Untoro J, Karyadi E, Wibowo L, Gross R: Effect of daily or weekly multiple-micronutrient and iron foodlike tablets on body iron stores of Indonesian infants aged 6-12 mo: a double-blind, randomized, placebo-controlled trial. Am J Clin Nutr 2007, 86(6):1680-1686

39. Zavaleta N, Respicio G, Garcia T: Efficacy and acceptability of two iron supplementation schedules in adolescent school girls in Lima, Peru. Nutr 2000, 130(2S Suppl):462S-464S

40. Sungthong R, Mo-Suwan L, Chongsuvivatwong V, Geater AF: Once weekly is superior to daily iron supplementation on height gain but not on hematological improvement among schoolchildren in Thailand. I Nutr 2002, 132(3):418-422.

41. Hop le T, Berger J: Multiple micronutrient supplementation improves anemia, micronutrient nutrient status, and growth of Vietnamese infants: double-blind, randomized, placebo-controlled trial. J Nutr 2005, 135(3):660S-665S.

42. Mejia LA, Chew F: Hematological effect of supplementing anemic children with vitamin $\mathrm{A}$ alone and in combination with iron. Am J Clin Nutr 1988, 48(3):595-600
43. Fishman SM, Christian P, West KP: The role of vitamins in the prevention and control of anaemia. Public Health Nutr 2000, 3(2):125-150.

44. Angeles IT, Schultink WJ, Matulessi P, Gross R, Sastroamidjojo S: Decreased rate of stunting among anemic Indonesian preschool children through iron supplementation. Am J Clin Nutr 1993, 58(3):339-342.

45. Lawless JW, Latham MC, Stephenson LS, Kinoti SN, Pertet AM: Iron supplementation improves appetite and growth in anemic Kenyan primary school children. J Nutr 1994, 124(5):645-654.

46. Murdiana A, Azis I, Saidin S, Jahari AB, Karyadi D: Vitamin A-fortified monosodium glutamate and vitamin A status: a controlled field trial. Am J Clin Nutr 1988, 48(5):1265-1270.

47. Hambidge KM: Zinc deficiency in young children. Am J Clin Nutr 1997, 65(1):160-161.

48. Chhagan MK, Van den Broeck J, Luabeya KK, Mpontshane N, Tomkins A, Bennish ML: Effect on longitudinal growth and anemia of zinc or multiple micronutrients added to vitamin A: a randomized controlled trial in children aged 6-24 months. BMC Public Health 2010, 10:145.

49. Allen $L H$ : Interventions for micronutrient deficiency control in developing countries: past, present and future. J Nutr 2003, 133(11 Suppl 2):3875S-3878S.

doi:10.1186/1475-2891-10-129

Cite this article as: Kounnavong et al:: Effect of daily versus weekly home fortification with multiple micronutrient powder on haemoglobin concentration of young children in a rural area, Lao People's Democratic Republic: a randomised trial. Nutrition Journal 2011 10:129.

\section{Submit your next manuscript to BioMed Central and take full advantage of:}

- Convenient online submission

- Thorough peer review

- No space constraints or color figure charges

- Immediate publication on acceptance

- Inclusion in PubMed, CAS, Scopus and Google Scholar

- Research which is freely available for redistribution

Submit your manuscript at www.biomedcentral.com/submit
C BioMed Central 